\section{SPECT V/Q Scans}

TO THE EDITOR: It was quite depressing to read yet another major collection of papers on the diagnosis and management of pulmonary embolism in Seminars in Nuclear Medicine, volume 38 , November 2008, in which only one of the articles, an excellent paper by Paul Roach et al. (1), mentioned SPECT ventilationperfusion (V/Q) scanning. This standard nuclear medicine imaging technique was virtually ignored by all the other authors, who wrote of planar V/Q imaging exclusively.

No one anywhere in the world would imagine using planar imaging for regional cerebral blood flow studies with ${ }^{99 \mathrm{~m}} \mathrm{Tc}-$ exametazime (Ceretec; GE Healthcare). This is because the superimposition of activity in overlying brain regions would allow only large perfusion defects in the brain to be seen on the planar images. SPECT is used routinely for precise definition of cerebral perfusion defects. This situation is completely analogous to that with V/Q lung scans.

I have been using SPECT V/Q lung scanning on my patients for 9 y. I use about $50 \mathrm{MBq}$ of ${ }^{99 \mathrm{~m}} \mathrm{Tc}$-Technegas (Cyclomedica Austalia Pty Ltd) for the ventilation studies, with an acquisition time of $15 \mathrm{~min}$, followed by $250 \mathrm{MBq}$ of ${ }^{99 \mathrm{~m}} \mathrm{Tc}$-macroaggregated albumin for the perfusion studies, with an acquisition time of $10 \mathrm{~min}$.

The reporting algorithm for these studies is simple. Any perfusion mismatch that you can visualize with our resolution can be called pulmonary embolism.

It is time, in 2009, that nuclear medicine physicians in the United States apply the best technology they have when doing V/Q scans for pulmonary embolism, and planar imaging is certainly not it. The old "I'm used to planar scans" approach must be abandoned in the interest of our patients. Who would go back to planar myocardial perfusion imaging or even think of using planar scans for cerebral blood flow?

Although I know that many love the PIOPED probabilistic approach to reporting V/Q scans and feel comforted when they can state confidently that the scan is indeterminate for pulmonary embolism, the referring physicians do not feel this comfort and are referring their patients more often for CT pulmonary angiography despite its significantly higher radiation burden.

The unfortunate issue for us working outside the United States is that although we are using SPECT V/Q imaging and are confident we are not missing clinically significant pulmonary embolism, our referring clinicians read the U.S. literature, which now regards CT pulmonary angiography as the routine screening test for pulmonary embolism. Our lung scan numbers have fallen as a result. The more the U.S. literature shows of complicated decision trees analyzing the probability that pulmonary embolism is present on planar lung scans, the fewer will be the patients who are referred for scans. As I said at the start, it is quite depressing.

\section{REFERENCE}

1. Roach PJ, Bailey DL, Harris BE. Enhancing lung scintigraphy with single-photon emission computed tomography. Semin Nucl Med. 2008;38:441-449.

COPYRIGHT @ 2009 by the Society of Nuclear Medicine, Inc.
Roger Uren

University of Sydney Newtown, Australia

DOI: 10.2967/jnumed.108.059832

REPLY: It is surprising that Dr. Uren chose to write his letter to the editor of The Journal of Nuclear Medicine rather than to Seminars in Nuclear Medicine to express concern over articles appearing in the November 2008 issue of Seminars. We welcome the opportunity Dr. Schelbert has given us to respond to Dr. Uren's comments.

As the founding and ongoing editors of Seminars for the past $38 \mathrm{y}$, we have always striven to present a balanced picture of subject matter in the journal, particularly when controversy exists-as is the case regarding the relative roles of ventilation-perfusion (V/Q) scintigraphy and CT angiography in the diagnosis of pulmonary embolism. Four of the 7 articles in the November issue dealt with non-V/Q aspects of the pulmonary embolism debate. These 4 were the clinical overview and the discussions of lower-extremity ultrasound, CT angiography, and MRI (PIOPED III introduction). So the "collection of papers" referred to by Dr. Uren boils down to 3 . One of the 3 specifically dealt with SPECT V/Q. The article by Freeman et al. (1) showed no illustrations and devoted a boldfaced paragraph to the virtues of SPECT. Perhaps Dr. Uren missed this, as he suggests that Dr. Roach's (2) was the only article that "mentioned" SPECT.

Dr. Uren's analogy between the use of ${ }^{99 \mathrm{~m} T c-e x a m e t a z i m e}$ (Ceretec; GE Healthcare) for brain studies and the use of V/Q for lung studies is misleading. From the first introduction of ${ }^{99 \mathrm{~m}} \mathrm{Tc}-$ exametazime, brain imaging was, of necessity, a SPECT study. In such a case, SPECT is essential in order to visualize small intracerebral structures, which cannot be seen with planar imaging. This situation is definitely not comparable to that with V/Q imaging, in which choices exist. His argument might have been better served if he had stuck with the myocardial perfusion analogy. The article by Freeman et al. (1) mentions that the $1 \%$ false-negative rate in the Canadian study, as well as the $1.1 \%$ false-negative rate in our Montefiore study, supports the accuracy of the planar study. These 2 false-negative rates are quite similar to the results of the only published SPECT study with follow-up - a study that quoted a 98.5\% negative predictive value (3). The rate of indeterminate interpretations in close to 2,000 planar V/Q studies performed at Montefiore during 2006 and 2007 was only $6.5 \%-7 \%$, which we suspect is comparable to the rate in SPECT. Planar imaging has been quite successful in accomplishing our goal of significantly reducing the number of CT angiograms at our institution.

Dr. Uren should be aware that Technegas (Cyclopharma Corp.) is not available in the United States. It is universally agreed that this is the best ventilatory agent. In a recent editorial in Nuclear Medicine Communications, Roach et al. (4) pointed out that SPECT must be performed with a superior ventilation agent, for example, Technegas and a software display package that allows coregistered V/Q scans. Most American nuclear medicine physicians are not opposed to SPECT. We are just waiting for Technegas to receive Food and Drug Administration approval, which will, we hope, occur within the next year. We will likely be moving to SPECT at that point. It is also important to mention that although SPECT may seem logically superior to planar imaging for pulmonary embolism, the 
literature has insufficient evidence to support this conclusion. Conclusions that are not derived from evidence-based medicine are often incorrect.

We regret that Dr. Uren found our November issue of Seminars "quite depressing." Perhaps another reading of the articles and a better understanding of why the unavailability of Technegas has inhibited SPECT V/Q growth in the United States would have allayed his concerns. Presently, planar V/Q imaging remains a valuable and reliable procedure in the diagnosis of pulmonary embolism.

\section{REFERENCES}

1. Freeman LM, Stein EG, Sprayregen S, et al. The current and continuing important role of ventilation-perfusion scintigraphy in evaluating patients with suspected pulmonary embolism. Semin Nucl Med. 2008;38:432-440.
2. Roach PJ, Bailey DL, Harris BE. Enhancing lung scintigraphy with single-photon emission computed tomography. Semin Nucl Med. 2008;38:441-449.

3. Leblanc M, Leveille F, Torcotte E. Prospective evaluation of the negative predictive value of V/Q SPECT using ${ }^{99 m}$ Tc-Technegas. Nucl Med Commun. 2007;28: 667-672.

4. Roach PJ, Bailey DL, Schembri GP. Reinventing ventilation/perfusion lung scanning with SPECT. Nucl Med Commun. 2008;29:1023-1025.

Leonard M. Freeman

M. Donald Blaufox

Montefiore Medical Center and

Albert Einstein College of Medicine

Bronx, New York 